\title{
Regional Rainfall Forecasting using Large Scale Climate Teleconnections and Artificial Intelligence Techniques
}

\author{
D. Nagesh Kumar, M. Janga Reddy and Rajib Maity \\ Department of Civil Engineering, Indian Institute of Science, \\ Bangalore-560 012, India
}

\begin{abstract}
This paper presents an Artificial Intelligence approach for regional rainfall forecasting for Orissa state, India on monthly and seasonal time scales. The possible relation between regional rainfall over Orissa and the large scale climate indices like El-Niño Southern Oscillation (ENSO), EQUitorial INdian Ocean Oscillation (EQUINOO) and a local climate index of Ocean-Land Temperature Contrast (OLTC) are studied first and then used to forecast monsoon rainfall. To handle the highly non-linear and complex behavior of the climatic variables for forecasting the rainfall, this study employs Artificial Neural Networks (ANNs) methodology. To optimize the ANN architecture, Genetic Optimizer (GO) is used. After identifying the lagged relation between climate indices and monthly rainfall, the rainfall values are forecast for the summer monsoon months of June, July, August, and September (JJAS) individually, as well as for total monsoon rainfall. The models are trained individually for monthly and for seasonal rainfall forecasting. Then the trained models are tested to evaluate the performance of the model. The results show reasonably good accuracy for monthly and seasonal rainfall forecasting. This study emphasizes the value of using large-scale climate teleconnections for regional rainfall forecasting and the significance of Artificial Intelligence approaches like $\mathrm{GO}$ and $\mathrm{ANNs}$ in predicting the uncertain rainfall.
\end{abstract}

Reprint requests to: D. Nagesh Kumar, Department of Civil Engineering, Indian Institute of Science, Bangalore-560 012, India; e-mail: nagesh@civil.iisc.ernet.in 


\section{KEYWORDS}

rainfall forecasting, large scale climate indices, ENSO, EQUINOO, artificial neural networks, genetic optimizer

\section{INTRODUCTION}

A reliable prediction of Indian Summer Monsoon Rainfall (ISMR) on monthly and seasonal time scales is not only scientifically challenging but also important for planning and implementing agricultural strategies in the country. The continuous changes in global climate and the uneven spatial and temporal distribution of rainfall are causes for severe problems like floods and droughts. For example, the Orissa state in India is facing similar problems more often. Most of the rainfall in the region occurs during monsoon period. The rainfall received during the four months, i.e., June, July, August, September (JJAS) is considered as summer monsoon and is very crucial for the farning community. Researchers have used various approaches to study and predict the seasonal and intra-seasonal rainfall. To forecast the rainfall at different spatial and temporal scales, the models used in the past can be broadly classified as empirical and dynamical (Sahai et al., 2000). This study is concerned with empirical models only. Empirical modeling strategies include identification of reliable precursors as well as optimal utilization of the information contained in the data on precursors. The reasonable success achieved by the empirical approach has motivated persistent exploration of regional/global teleconnections of the Indian summer monsoon season since Walker's time, which resulted in a large number of predictors as well as a variety of statistical techniques. Because any modeling effort will have to be based on an understanding of the variability of the past data, ANNs have some special characteristics in this regard to be used. In contrast to conventional modeling approaches, ANNs do not require an in-depth knowledge of driving processes, nor do they require the form of the model to be specified a priori (Haykin, 1999). This is true when modeling various climate variables for forecasting of hydrological variables like rainfall and streamflows. In view of this, ANNs are found to be a suitable approach for 
the prediction of Indian monsoon rainfall using large scale climate variables as input to the network. The next section provides a brief overview of climate variables and their influence on Indian monsoon rainfall.

\section{INFLUENCE OF CLIMATE VARIABLES ON INDIAN MONSOON}

At present, the assessment of the nature and causes of seasonal climate variability is still uncertain. There are still uncertainties associated with local and global climatic variables. For any rainfall prediction model, these are sources of variance in predictability (Kumar et al., 1995). Recently, researchers have studied the influence and the possible relationships between various global climate variables and Indian monsoon rainfall. Additionally, they brought out several regional parameters based on sea-level pressure, temperature, and wind fields over India and sea surface temperature (SST) data from the adjoining Indian seas. Although their performance in seasonal forecasting has been encouraging, there is still a large variance in the monsoon rainfall unaccounted by the predictors identified so far (Kumar et al., 1997).

Several observational and modeling studies have indicated that the slowly varying surface boundary conditions, particularly in the winter and pre-monsoon seasons, constitute a major forcing factor on the inter-annual variability of the monsoon rainfall. Parameters representing these conditions, global as well as regional, provide a handle for seasonal prediction. On interannual timescales, the Indian monsoon rainfall has a strong and positive correlation with the premonsoon spring tropospheric temperature anomaly (Verma, 1980; Parthasarathy et al., 1990; Singh \& Chattopadhyay, 1998). Factors that influence the Indian summer monsoon include the sea surface temperature in the Pacific and Indian oceans (Zveryaev, 2002), the Indian Ocean Dipole Mode (Saji et al., 1999), Eurasian snow cover (Kripalani and Kulkarni, 1999; Fasullo, 2004), the Atlantic circulation variation (Chang et al., 2001), global warming and human activities, among others. In the subsequent sections some of the highly influencing large scale climate indices, like El-Niño Southern Oscillation (ENSO), EQUitorial INdian Ocean Oscillation (EQUINOO) and Ocean-Land Temperature Contrast (OLTC) are discussed. 


\subsection{El-Nifio Southern Oscillation (ENSO)}

The planetary-scale tropical Sea Level Pressure (SLP) anomalies associated with the Southern Oscillation (SO) occur in conjunction with the episodes of large-scale sea surface temperature (SST) anomalies (El-Nifo/La Niffa) over the tropical Pacific region (Shukla \& Paolino, 1983; Rasmusson \& Carpenter, 1983). The intensities of El-Niffo events are generally assessed on the basis of the average SSTs over the Niño regions in the Pacific Ocean, widely known as NNO1 $+2\left(0^{\circ}-10^{\circ} \mathrm{S}, 80^{\circ} \mathrm{W}-90 \mathrm{~W}\right)$, NNO3 $\left(5^{\circ} \mathrm{S}-5^{\circ} \mathrm{N}, 90^{\circ}\right.$ $\left.\mathrm{W}-150^{\circ} \mathrm{W}\right), \mathrm{NINO} 3.4\left(5^{\circ} \mathrm{S}-5^{\circ} \mathrm{N}, 120^{\circ} \mathrm{W}-170^{\circ} \mathrm{W}\right)$ and NINO4 $\left(5^{\circ} \mathrm{S}-5^{\circ} \mathrm{N}\right.$, $160^{\circ} \mathrm{E}-150^{\circ} \mathrm{W}$ ). After the discovery of strong links between the El-Nifo Southern Oscillation (ENSO) and the ISMR (Sikka, 1980; Pant \& Parthasarathy, 1981; Rasmusson \& Carpenter, 1983; Rao, 1997), the empirical models for monsoon prediction have developed rapidly. Many studies have used the relation of ENSO to forecast Rainfall (Pant \& Parthasarathy, 1981; Rasmusson \& Carpenter, 1983; Parthasarathy, et al., 1988) over the Indian sub-continent. Parthasarathy et al. (1988) found that NINO 4 SSTs are having significant relation with the ISMR, whereas others observed that NINO3 SSTs (Ashok et al. 2004), and NINO3.4 SSTs (Gadgil et al. 2003 and 2004) present better relationship with ISMR.

\subsection{Equatorial Indian Ocean Oscillation (EQUINOO)}

More recently, Gadgil et al. (2003, 2004) established a possible link of the Indian monsoon to events over the equatorial Indian Ocean. According to (Gagdil et al., 2004; Maity \& Nagesh Kumar, 2006), over the equatorial Indian Ocean, enhancement of deep convection in the atmosphere over the western part is generally associated with suppression over the eastern part and vice versa. The oscillation between these two states, which is reflected in the pressure gradients and the wind along the equator, is known as Equatorial Indian Ocean Oscillation (EQUNNOO). The index of EQUINOO is based on the negative of the anomaly of the zonal component of surface wind in the equatorial Indian Ocean region $\left(60^{\circ} \mathrm{E}-90^{\circ} \mathrm{E}, 2.5^{\circ} \mathrm{S}-2.5^{\circ} \mathrm{N}\right)$. This index is known as Equatorial zonal Wind Index (EQWIN) (Gagdil et al., 2004). They 
also showed that every season with excess rainfall/drought during 1979-2002 can be 'explained' in terms of favorable/unfavorable phase of either the EQUINOO or the ENSO or both. For example in 1994, ENSO was unfavorable, but EQUINOO was favorable and India received above normal rainfall. On the other hand in 1979 and 1985, ENSO was favorable, but EQUINOO was unfavorable and India received a below normal rainfall. Hence they suggested that by using those two climate indices together, the predictability of Indian monsoon rainfall can be improved

\subsection{Ocean-Land Temperature Contrast (OLTC)}

In the past, few studies emphasized that generation of the Indian summer monsoon can be attributed to the land-sea thermal contrast and it was also observed that the thermal conditions during the pre-monsoon season over India can play a significant role in the performance of the ensuing monsoon (Mooley \& Paolino, 1988; Parthasarathy et al., 1990). Various studies have used this phenomenon in predicting summer monsoon and found that regional temperature data can be a useful predictor for summer monsoon rainfall prediction (Mooley \& Paolino, 1988; Parthasarathy et al., 1990; Kumar et al., 1997). Sahai et al. (2003) have used the links of global SST data with Indian monsoon seasonal data and produced successful results in forecasting ISMR. Recently it is found that OLTC, the difference of SSTA over the region of $\left(10^{\circ} \mathrm{S}-10^{\circ} \mathrm{N}, 60^{\circ} \mathrm{E}-85^{\circ} \mathrm{E}\right)$ and the anomalous surface air temperature over east coast of India, is having better relationship with Indian monsoon rainfall

All these factors have some influence, but it is not clear as to what amount of variance is caused by each of these climate variables on rainfall predictability. Hence, in this study we have chosen the highly influencing global climate variables ENSO, EQUINOO, and OLTC to predict the Indian summer monsoon rainfall. To represent the ENSO event, Nino3.4 Sea Surface Temperature Anomaly (NINO 3.4 SSTA), for EQUINOO, equatorial zonal wind index (EQWIN) at equator $\left(2.5^{\circ} \mathrm{S}-2.5^{\circ} \mathrm{N}, 60^{\circ} \mathrm{E}-90^{\circ} \mathrm{E}\right)$, and for OLTC, the difference of SSTA over the region of $\left(10^{\circ} \mathrm{S}-10^{\circ} \mathrm{N}, 60^{\circ} \mathrm{E}-85^{\circ} \mathrm{E}\right)$ and the surface air temperature over east coast of India are used in this study 


\section{FORECASTING INDIAN SUMMER MONSOON RAINFALL}

Most of the models that were used to forecast ISMR come under empirical modeling approach. A general overview of forecasting models for Indian monsoon rainfall can be found in (Gadgil et al., 2002). Excellent reviews of the empirical models used for prediction of ISMR are presented in (Kumar et al., 1995; Sahai et al., 2003). In this study, we considered ANNs as the forecasting tool. A brief description of application of ANNs for rainfall forecasting is given below.

Artificial Neural Networks have been used in various fields for the prediction and forecasting of complex nonlinear time series, including the forecasting of Indian monsoon rainfall. The neural network technique is able to learn the dynamics within the time series data (Elsner \& Tsonis, 1992). In the past, ANNs have been successfully used to predict Indian monsoon rainfall (Goswami \& Srividya, 1996; Venkatesan et al., 1997; Guhathakurta et al., 1999; Iyengar \& Raghu Kanth, 2005). Goswami and Srividya used the time series approach, in which previous values from the time series were used to predict future values.

Venkatesan et al. (1997) have used neural network technique to predict monsoon rainfall of India using few predictors and compared the results with linear regression techniques, showing that the model based on neural network technique performed better. Guhathakurta et al. (1999) have used hybrid principal component and Neural Network approach for long range forecasting of the Indian summer monsoon rainfall. They observed improved accuracy in prediction. The neural network technique contains the advantages of both the regression analysis and nonlinear dynamics that need to be incorporated in order to predict the dynamic rainfall values.

Sahai et al. (2000) applied the ANN technique to five time series of June, July, August, September monthly and seasonal rainfall. The previous five years values from all the five time-series were used to train the ANN to predict for the next year. They found good performance in predicting rainfall. Other studies, which have used ANNs for summer monsoon rainfall forecasting over India, include Iyengar and Raghukanth (2005). They decomposed the Indian monsoon rainfall data into six empirical time series (intrinsic mode functions). Then they have identified the first empirical mode 
as a nonlinear part and the remaining as the linear part of the data. The nonlinear part is handled by ANN techniques, whereas the linear part is modeled through simple regression. They showed that their model can explain 75 to $80 \%$ of the inter-annual variability (IAV) of eight regional rainfall series, considered in their study.

\section{ARTIFICIAL NEURAL NETWORKS METHODOLOGY}

Neural Networks are used to detect hidden relations in the set of patterns given during training period. In this study Feed-forward ANN procedure is used. A typical ANN will have an input layer, an output layer and one or more hidden layers. Neurons in the input layer simply act as a buffer to next layer. The neurons in different layers are connected by means of weights. The neurons in the hidden and output layers use activation function to transfer the received input to the next layer neurons. The activation function adopted is a Fermi function, which is given as follows.

$$
f(x)=\frac{1}{1+e^{-4(x-0.5)}}
$$

The input to each neuron in the hidden layer is the sum of weighted input signals from the neurons of the previous layer. The neuron will use the transfer function and outputs the signal to next layer, which will become input to the neurons in the next layer and so on. The same procedure will be followed for all neurons of different layers. Once the output signals are found at output layer, they will be compared with the actual observed values and the error is back propagated into the network. The most commonly used ANN training algorithm, Back Propagation (BP) algorithm, is adopted to train the ANNs. The Back Propagation Neural Network (BPNN) uses steepest gradient descent procedure. Detailed description of working of ANNs can be found in any standard reference (for example, Haykin, 1999).

The ANNs learning is the process of finding the optimal weight matrices in a systematic manner, in order to achieve the desired value of target outputs. The performance measure used to train ANNs is minimizing the network 
error function, which is given as

$$
E=\sum_{i=1}^{D} \sum_{j=1}^{g}\left(y_{i, j}-y_{i, j}^{t}\right)^{2}
$$

where, $y_{i, j}^{t}$ is desired (target) value for $j^{\text {th }}$ output node and $t^{\text {th }}$ pattern; $y_{i j}$ is computed value for $j^{\text {th }}$ output node and $i^{\text {th }}$ pattern; $q$ is number of output nodes; and $p$ is number of training patterns.

The selection of a suitable ANN architecture will play a significant role in performance of the model. If the architecture is too small, the network may not have sufficient degree of freedom to leam the process correctly. On the other hand if the network is too large, it may not converge during training, or it may overfit the data (Haykin, 1999). In general, the architecture of the network is finalized after a number of trials. The features of network architecture most commonly optimized are the number of hidden layers and the number of nodes in the hidden layer. In general, initially the architecture begins with a very small network and several parameters are varied including the number of hidden layers and the number of nodes in the hidden layer to obtain an appropriate architecture for each data set. In this study to optimize the ANNs architecture, Genetic Optimizer is used. A brief description of working procedure of the genetic optimizer with neural network is given below.

\subsection{Genetic Optimizer-Neural Networks}

The main steps involved in Genetic optimizer with ANN are as follows.

1. Initialize parameters: First all the parameters like population size $(N)$, number of maximum generations, probability of crossover $\left(P_{c}\right)$ and probability of mutation $\left(P_{n}\right)$ are to be set to specific values.

2. Generate initial population: At initial generation, the Genetic Optimizer randomly creates networks for the initial population, which is equal to the size of population $(\mathrm{N})$.

3. Train the network and evaluate fitness: Each network within the current generation is to be trained with BPANN and their fitness values are determined according to the goals to be achieved.

4. Propagation of networks: a new generation of networks will be created from the old one according to the following procedure: 
a. Two "parent" networks will be chosen out of the old generation. The selection algorithm will choose networks with a high fitness by a higher probability.

b. Two "children" networks will be created from the two "parent" networks. Using the cross over probability, $P_{c}$, the two "parent" networks will be crossed over, i.e., they will swap a portion of the network with each other.

c. The "children" will be mutated with a mutation probability, $P_{m}$. Here, mutation means insertion or deletion of a layer and/or insertion or deletion of a neuron into a layer.

d. A few elitist members of the population in current generation are carried to next generation. The selection continues until the new generation has $\mathrm{N}$ members too. After completion the new generation will be evaluated.

5. Check for Termination Criteria: Stop the evolution, if the target level is achieved or the pre-set maximum number of generations is reached; else increment the generation counter and go to step (3), repeat the evolution.

6. Output the best solution obtained so far during the evolution.

The input and output patterns are scaled to 0-1 range through mapping with the help of minimum and maximum values of the patterns, whereby it can be modeled using Fermi function [Eq. (1)]. This scaling helps the algorithms towards faster convergence. For ANNs training, the termination criteria used to stop the learning process are, either the epoch counter reaches 1000 or the maximum value of squared deviation of neural network output from the observed value among all training patterns is less than 0.001 . To avoid over fitting, first the model is trained with BPANN using training data set, then the model is cross validated, by testing its performance with validation data set, which was not used during training period. In this process the model makes better generalization for the new data set.

\section{DATA}

The study uses data on various parameters, viz., monthly NNO3.4 SSTA, EQWIN index, OLTC index and monthly rainfall anomaly over Orissa subdivision. Monthly Nino3.4 SSTA and SSTA for region $\left(10^{\circ} \mathrm{S}-10^{\circ} \mathrm{N}, 60^{\circ}\right.$ 
E - 85 $5^{\circ}$ E) (1958-1990) data have been collected from the web site of Climate Analysis Centre, National Centre for Environmental Prediction (NCEP), USA (www.cpc.ncep.noaa.gov/); Wind data (1958-1990) have been collected from NCEP, USA (www.cpc.ncep.noaa.gov/) to obtain EQWIN index for EQUINOO ([20], [21]). Monthly rainfall and temperature data (1901-1990) have been collected from the web site of Indian Institute of Tropical Meteorology (http://www.tropmet.res.in/).

\section{MODEL SELECTION}

To identify the months that can be used as input to the ANNs model, cross correlation analysis is carried out for predictor variables. The inputs driven to the ANNs are monthly Nino 3.4 SSTA, EQWIN and the OLTC indices. The output variable is rainfall. Table 1 gives a complete list of inputs that have been used for forecasting the rainfall for June, July, August, September months and for the monsoon season (JJAS).

\section{TABLE 1}

Climate indices of predictor variables considered for rainfall prediction of June, July, August, September months and for summer monsoon (JJAS)

\begin{tabular}{|c|c|}
\hline Rainfall & Predictor variables considered \\
\hline June & Nino 3.4 (Feb, March, April), EQWIN (May, June), OLTC (May, June) \\
\hline July & Nino 3.4 (Feb, March, April), EQWIN (June, July), OLTC (June, July) \\
\hline Aug & (Feb, March, April), EQWIN (July, Aug), OLTC (July, Aug) \\
\hline Sep & (Feb, March, April), EQWIN (Aug, Sep), OLTC (Aug, Sep) \\
\hline JJAS & Nino 3.4 (Feb, March, April), EQWIN (May, June), OLTC (May, June) \\
\hline
\end{tabular}

The predictor variable data set is available for 33 years (1958-1990). To train the ANNs, 23 years data set is selected and then to test the performance of the trained model, the remaining 10 years data set is used. The models are trained with different combinations of network architectures by using genetic optimizer. For genetic optimizer the parameters adopted are as follows: 
population size (number of networks created per generation) $=50$; maximum number of generations $=100$; probability of crossover (probability for a child network to be crossed over with another child network), $P_{c}=0.6$ and probability of mutation (probability for a network to be modified during rollover to a new generation), $P_{m}=0.04$. For BPANN the parameters adopted are, learning parameter $=0.2$; momentum parameter $=0.1$; maximum number of epochs $=1000$. The best suited network architecture obtained for different monthly and seasonal models is given in Table 2.

\section{TABLE 2}

Architecture of ANNs selected and the performance of the models for rainfall forecasting in the monsoon season for Orissa sub-division

\begin{tabular}{llll}
\hline Month/Season & \multirow{2}{*}{ Network Architecture } & \multicolumn{2}{c}{ Correlation Coefficient (CC) } \\
\cline { 3 - 4 } & & Training & Testing \\
\hline June & $7,7,7,1$ & 0.9941 & 0.8349 \\
July & $7,8,9,1$ & 0.9994 & 0.8002 \\
August & $7,10,1$ & 0.9969 & 0.8102 \\
September & $7,8,1$ & 0.9998 & 0.5775 \\
JJAS & $7,8,1$ & 0.9975 & 0.8951 \\
\hline
\end{tabular}

\section{RESULTS AND DISCUSSION}

By using the Genetic Optimizer-ANNs methodology, the regional rainfall for Orissa state has been forecast. For the June month ANN model, the correlation coefficient (CC) values obtained are 0.9941 and 0.8349 during training and testing periods respectively. Figure la shows the comparison of ANN forecasted rainfall with observed rainfall for June. It can be seen that, except for one year (1986) the model results are within reasonable accuracy and it predicts well the low rainfall $(1981,1982,1983,1987)$ as well as high rainfall $(1984,1989)$ values during the testing period. For July month, the CC values obtained are 0.9994 and 0.8002 during training and testing periods respectively. Figure lb shows the comparison of ANN model forecasted rainfall with observed rainfall for July during the testing period. It can be 

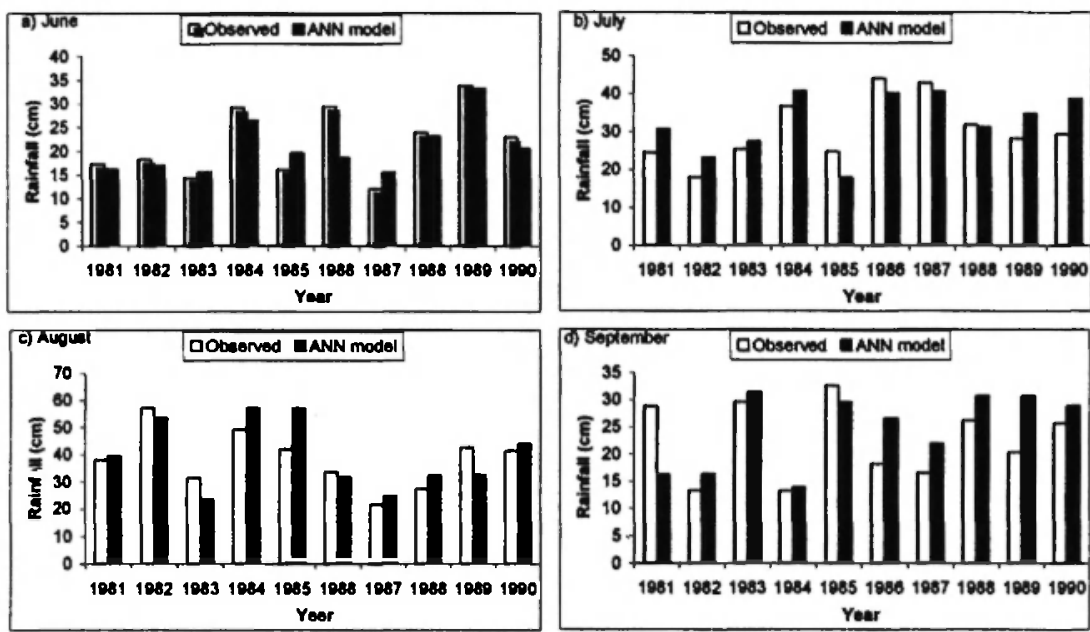

Fig. 1: Comparison of rainfall predicted for (1981-1990) using ANN model and observed rainfall for the months (a) June; (b) July; (c) August; (d) September.

observed that, even though there are a few deviations from observed rainfall $(1981,1982,1985,1989,1990)$, the model shows reasonable accuracy. For August month, the $\mathrm{CC}$ values obtained are 0.9969 and 0.8102 during training and testing periods respectively. Figure lc shows, the comparison of ANN model forecasted rainfall with observed rainfall for August month during the testing period. The model results show that for two years, ANN over forecasted $(1984,1985)$, for two years under forecasted $(1983,1989)$ and for the remaining years forecasts are in reasonable agreement. For September month model, the $\mathrm{CC}$ values obtained are 0.9998 and 0.5775 during training and testing periods respectively. Figure Id shows the comparison of ANN forecasted rainfall with observed rainfall for September month during the testing period. It can be observed that the model has under forecasted for one year $(1981)$, over forecasted for four years $(1986,1987,1988,1989)$ and for the remaining years the results are in reasonable accuracy.

Similarly, the ANN model is trained for summer monsoon season, JuneSeptember (JJAS) rainfall forecasting. Figure 2 shows, the comparison of observed rainfall with ANN model forecasted rainfall for monsoon season (JJAS) during testing period. The CC values obtained for JJAS seasonal model are 0.9975 and 0.8951 during training and testing periods respectively. The model results are within reasonable accuracy with observed rainfall for 


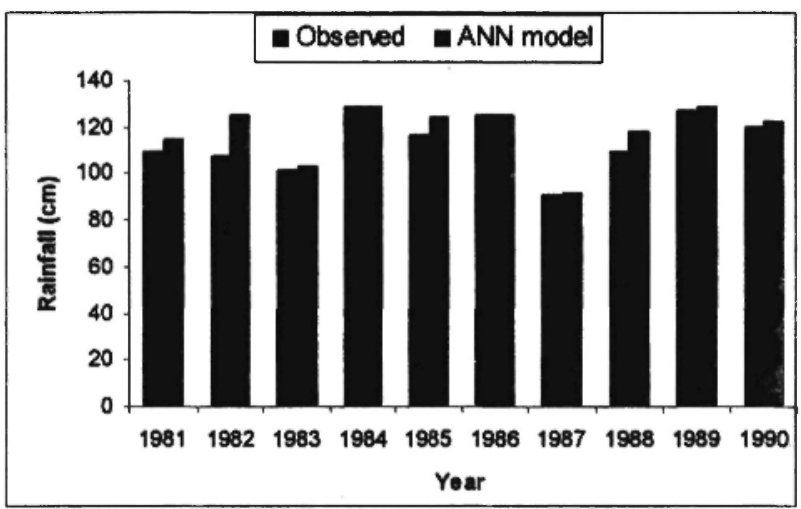

Fig. 2: Comparison of rainfall predicted for (1981-1990) using ANN model and observed rainfall for summer monsoon (JJAS)

most of the seasonal rainfall values, except minor deviation for one year (1982).

Here it can be noticed that, when the monthly rainfall forecasting is compared with seasonal rainfall forecasting performance, seasonal rainfall model is performing better than monthly models. This may be because the dynamic nature of climate variables causes more uncertainty in monthly time scale than seasonal scale, thus larger variability can be observed in intraseasonal rainfall prediction.

\section{CONCLUSIONS}

The climate indices of ENSO (Nino 3.4 SSTA), EQUNOO (EQWIN), and Ocean-Land Temperature Contrast (OLTC) have been used as predictor variables to predict the monthly as well as seasonal rainfall. After investigating the global climate variables that are highly influencing the regional rainfall, correlation analysis is carried out to select the monthly climate indices that have more influence on the individual monthly and seasonal rainfall. In a highly nonlinear time-series, to handle multiple variable influences on the rainfall prediction, ANNs have been adopted. Genetic optimizer is used to optimize the network architecture of ANNs. The models are trained and tested for individual months and for seasonal rainfall as a 
whole. The obtained results are encouraging and show improvement in rainfall forecasting. Incorporation of global climate information into rainfall prediction is thus very much useful and ANNs are found to be a suitable technique for this purpose.

\section{ACKNOWLEDGMENTS}

This work is partially supported by Dept. of Science and Technology, Govt. of India, through a project \# ES/48/010/2003 and INCOH, Ministry of Water Resuurces, Govt. of India, through project \# 23/52/2006-R\&D.

\section{REFERENCES}

Ashok, K., Guan, Z., Saji, N.H., and Yamagata, T. 2004. Individual and combined influences of ENSO and the indian ocean dipole on the indian summer monsoon Journal of Climate, 17, 3141-3155.

Chang, C.-P., Harr, P. and Ju, J. 2001. Possible roles of atlantic circulations on the weakening indian monsoon rainfall-ENSO relationship. Journal of Climate, 14, 2376-2380.

Elsner, J. B., Tsonis, A. A. 1992. Nonlinear prediction, chaos and noise. Bulletin of the American Meteorological Society, 73, 49-60.

Fasullo, J. 2004. A stratified diagnosis of the indian monsoon-eurasian snow cover relationship. Journal of Climate, 17, 1110-1122.

Gadgil, S., Srinivasan, J., Nanjundaiah, R.S., Kumar, K.K., Minot, A.A. and Kumar, R.K. 2002. On forecasting the Indian summer monsoon: The intriguing season of 2002. Current Science, 83, 394-403.

Gadgil, S., Vinayachandran, P. N. and Francis, P. A. 2003. Droughts of the Indian summer monsoon: Role of clouds over the Indian Ocean, Current Science, 85 (12), 1713-1719.

Gagdil, S., Vinayachandran, P. N., Francis, P. A. and Gadgil, S. 2004. Extremes of the Indian summer monsoon rainfall, ENSO and equatorial Indian Ocean oscillation, Geophysical Research Letters, 31, L12213, doi:10.1029/2004GL019733.

Goswami, P., Srividya 1996 A novel neural network design for long range prediction of rainfall pattern, Current Science, 70 , 447-457.

Guhathakurta, P., Rajeevan, M. and Thapliyal, V. 1999. Long range fore-casting Indian summer monsoon rainfall by a hybrid principal component neural network Model, Meteorological Atmospheric Physics, 71, 255-266. 
Haykin, S. 1999. Neural networks, New York, NY, USA, MacMillan Publishing Company.

lyengar, R.N. and Raghu Kanth, S.T.G. 2005. Intrinsic mode functions and a strategy for forecasting Indian monsoon rainfall. Meteorological Atmospheric Physics, 90(1-2), 17-36.

Kripalani, R.H. and Kulkarni, A. 1999. Climatology and variability of historical Soviet snow depth data: Some New Perspectives in SnowIndian Monsoon Teleconnections. Climate Dynamics, 15, 475-489.

Kumar, K.K., Rupa Kumar, K. and Pant, G. B. 1997. Pre-monsoon maximum and minimum temperatures over India in relation to the summer monsoon rainfall, International Journal of Climatology, 17, 1115-1127.

Kumar, K.K., Soman, M. K. and Rupakumar, K. 1995. Seasonal forecasting of Indian summer monsoon rainfall: A review. Weather, 150, 449-467.

Maity, R. and Nagesh Kumar, D. (2006), Bayesian dynamic modeling for monthly Indian summer monsoon rainfall using El Niffo Southern Oscillation (ENSO) and Equatorial Indian Ocean Oscillation (EQUINOO), Journal of Geophysics Research, 111 , D07104, doi:10.1029/2005 JD006539.

Mooley, D. A. and Paolino, D. A. 1988. A predictive monsoon signal in the surface level thermal field over India', Monthly Weather Review, 116 (1), 256-264.

Pant, G.B. and Parthasarathy, B. 1981. Some aspects of an association between the southern oscillation and Indian summer monsoon. Archives of Meteorological Geophysics Biokl., Sr. B., 29, 245-251.

Parthasarathy, B., Diaz, H.F. and Eischeid, J.K. 1988. Prediction of all India summer Monsoon Rainfall with Regional and large-scale parameters. Journal of Geophysics Researc, 93 (5), 5341-5350.

Parthasarathy, B., Rupa Kumar,K. and Sontakke, N.A. 1990. Surface and upper air temperatures over India in relation to monsoon rainfall. Theoretical and Applied Climatology, 42, 93-110.

Rao, G.N. 1997. Interannual variations of monsoon rainfall in Godavari river basin-connections with the southern oscillation, Journal of Climate, 11, 768-771.

Rasmusson, E.M and Carpenter, T.H. 1983. The relationship between eastern equatorial Pacific Sea surface temperature and rainfall over India and Srilanka, Monthly Weather Review, 111, 517-528.

Sahai, A. K., Soman, M. K. and Satyan, V. 2000. All India summer monsoon rainfall prediction using an artificial neural network, Climate Dynamics, 16, 291-302.

Sahai, A.K., Grimm A.M., Satyan V. and Pant G.B. 2003. Long-lead prediction of Indian summer monsoon rainfall from global SST evolution, Climate Dynamics, 20, 855-863.

Saji, N.H., Goswami, B.N., Vinayachandran, P.N. and Yamagata, T. 1999. A dipole mode in the tropical Indian Ocean, Nature, 401, 360-363. 
Sikka, D.R. 1980. Some aspects of the large-scale fluctuations of summer monsoon rainfall over India in relation to fluctuations in the planetary and regional scale circulation parameters. Proceedings of the Indian Academy of Sciences (Earth. Planet. Sci.), 89, 179-195.

Singh, G.P. and Chattopadhyay, J. 1998. Relationship of tropospheric temperature anomaly with Indian southwest monsoon rainfall. International Journal of Climatology, 18, 759-763.

Shukla, J. and Paolino, D. A. 1983. The southern oscillation and long-range forecasting of the summer monsoon rainfall over India, Monthly Weather Review, 111, 1830-1837.

Venkatesan, C., Raskar, S.D., Tambe, S.S., Kulkarni, B.D. and Keshavamurty, R. N. 1997. Prediction of all India monsoon rainfall using errorback-propagation neural networks. Meteorological Atmospheric Physics, 62, 225-240.

Verma, R.K. 1980. Importance of upper tropospheric thermal anomalies for long-range forecasting of Indian summer monsoon activity. Monthly Weather Review, 108, 1072-1075.

Zveryaev, I.I. 2002. Interdecadal changes in the zonal wind and the intensity of intraseasonal oscillations during boreal summer Asian monsoon. Tellus, 54A, 288-298. 